\title{
How a social worker could alleviate psychosocial problems of families accessing a child development clinic in Colombo
}

\author{
Verity Slee $^{1}$, S M Senanayake ${ }^{2}$, M P Senanayake ${ }^{3}$ \\ Sri Lanka Journal of Child Health, 2008; 37: 48-51
}

(Key words: social worker, psychosocial problems, families accessing child development clinic)

\begin{abstract}
Objectives To describe psychosocial issues faced and the services available to children accessing the child development clinic and how a social worker could help extend services provided through the clinic.

Design A cross sectional descriptive qualitative study.

Method All children attending the weekly clinic were seen by a social work researcher and medical officer, over a period of seven months and in-depth interviews conducted on twenty five selected patients with significant psychosocial problems. The parent or accompanying care giver was enrolled through a volunteer process and subjected to an open ended consultation on problems faced, services available and accessed, and reasons for not accessing same. A study was made of disability services in the community.
\end{abstract}

Results All patients had psychosocial problems of varying degree. Twenty five children in whom social problems caused a significant adverse impact on the capacity of care givers in providing care and therapy included a broad range of complex issues. Financial concerns, poor utilization of government and non governmental support schemes, inadequacy of suitable transport, dearth of facilities for appropriate schooling, social isolation, lack of respite for caregivers and siblings, family disharmony, alcoholism, and absence of counseling services were among these. Viable options for solving identified problems and the ways in which a social services officer could assist in each situation are described.

\footnotetext{
${ }^{1}$ Social Worker, Australian Youth Ambassadors for Development, ${ }^{2}$ Demonstrator, ${ }^{3}$ Professor of Paediatrics, Faculty of Medicine, University of Colombo.
}

(Received on 16 November 2007. Accepted on 20 December 2007)
Conclusion Families of children with disabilities face several difficulties in accessing services. Even when relevant services are available they are not competent to obtain these and are in need of extra help. A hospital based social services officer working within the team of the CDC could fulfill this role, effectively connecting government policy with the people it targets.

\section{Introduction}

Children with disabilities (CWD) are a disadvantaged population, vulnerable to stigmatization, discrimination, and exploitation. An estimated eighty five percent of CWD, are reported to live in developing countries where lack of access to appropriate services is a recognized cause of secondary and chronic disabilities ${ }^{1,2}$.

The Sri Lankan Government has made a formal commitment to supporting CWD and their families in the National Policy for Disability (2003) wherein it is stated that "Knowledge, skills, advice and counseling required to support each child who has a disability will be made available to them (parents and other family members) to fulfill their responsibilities" ". As a signatory to the United Nations Child Rights Convention (UNCRC) it is mandatory by law that CWD in Sri Lanka have access to services that meet their needs.

The dearth of child disability related data in Sri Lanka is a significant drawback to service provision ${ }^{2}$. The Child Development Clinic run by the University Paediatric Department at the Lady Ridgeway Children's Hospital provides assessment, counseling, therapy and referral pathways for a wide range of CWD and their families. It is therefore a suitable forum for assessment of whether families of CWD access government or non governmental schemes, and of their awareness of available resources. The University Child Development Clinic (CDC) provides medical and related services at the Lady Ridgeway Children's Hospital but its regular team does not contain a social worker. We set out to 
investigate the psychosocial problems and support received by a cohort of children accessing the CDC.

\section{Objectives}

- To describe psychosocial issues faced and the services available to children accessing the CDC.

- To describe how a social worker could help extend services provided through the clinic.

\section{Design}

A cross sectional descriptive qualitative study

\section{Method}

A social work researcher with a background in psychology and social health and a medical officer who helped collect clinical data while functioning as an interpreter carried out this research in the child development clinic at weekly clinic sessions held over a period of seven months. Twenty five patients with significant psychosocial problems were selected for in depth interviews. The parents or accompanying caregivers were enrolled through a volunteer process with confidentiality and anonymity being assured. A case note template was used for gathering information but open ended consultations were encouraged. The interviews focused on problems faced, services available and accessed, and where applicable, reasons for not accessing same.

\section{Results}

Majority of patients were of low income families and lived in and around Colombo. Twenty five children in whom social issues caused a significant adverse impact on the capacity of care givers and the care and therapy received were studied in depth.. One case history is presented.

\section{Case history}

S P was an 11 year old boy with global development delay, regular seizures, hyperactive behaviour and visual impairment. The family had not accessed any social benefits except for monthly visits to the nearby hospital by the mother who was the main caregiver. She did so to collect his anti-epileptic medication.

He was not schooling and had no socializing outside home. When the family went out he was locked in a room alone despite the fact that he regularly fell and hurt himself. Inside his home the CWD was sometimes contained in a separate section. His behaviour upset the family and according to the mother, was the reason for restricted interaction with siblings. One brother reluctantly assisted with the care when the mother requested.

His only source of stimulation was watching television when his brothers were out. The CWD bit himself often, which the mother interpreted as hunger. He had received physiotherapy until he was six years old and was taken out of the home for these sessions by the family until he became too heavy for the mother to physically carry him. The father had to assist in bringing for physiotherapy and thereby lost wages. These difficulties led to stopping of this therapy. He had no access to special aids which could have assisted him move about the house and minimize injuries.

The mother did not leave him alone with any other person for fear he would get abused due to his behaviour. She had similar fears of the school environment. The family had little access to support services and the mother (principal caregiver) was struggling to cope. She became very upset throughout both consultations specially when relating locking him in a room. She was very reluctant to discuss details at the first consultation, but began disclosure at subsequent meetings.

A broad range of complex issues were identified. A summary of these psychosocial problems is as follows:

- Financial constraints

- Inadequacy of suitable transport

- Dearth of facilities for appropriate schooling

- Social isolation

- Poor utilization of government and non governmental support schemes

- Lack of respite for caregivers and siblings

- Family disharmony

- Alcoholism

- Abandonment by the father or mother

- Lack of access to counselling services

How a social service officer (SSO) could have helped has been detailed below:

\section{Financial constraint}

This was the most commonly reported factor as hampering appropriate care and therapy. Despite a free health service, additional expenses for transport, special aids and employment of caregivers were not affordable. Provision of financial assistance through 
the Ministry of Social Services is an established government strategy but only one family had benefited. Lack of awareness or difficulties of access were reasons given by the others who perceived caring for the disabled child as a financial burden. They welcomed assistance from a SSO who was able to:

- access social services schemes by providing information, referral, liaison

- $\quad$ investigate and certify on need for support and financial assistance

- $\quad$ provide advocacy for social security and support

\section{Inadequacy of suitable transport}

Barriers to transport was the second most commonly reported problem. Inability to find appropriate public transport for CWD with behavioural and mobility impairments was mentioned by $88 \%$. Mothers reported difficulties in carrying older and heavier children and as a result fathers had to forego work. Poor compliance with therapy, secondary disabilities and social isolation were the results. A SSO was able to:

- lobby for implementation of government policy of providing transportation to CWD (Article 9 of the National Policy on Disability)

- link with community-based NGOs to access assistive devices and suitable transport

\section{Dearth of facilities for appropriate schooling}

Opportunities for schooling were less than those enjoyed by siblings. Many had never attended school and the reasons varied from lack of special education units locally, problems with transport, lack of confidence in the school's facilities and supervision, fears about the CWD's ability to cope, child's "difficult" behaviour, severity of disability, lack of appropriate toilet facilities at special education centres and the low priority given by parents towards education of the CWD. A SSO was able to:

- educate families on value of appropriate education for CWD.

- make referral to appropriate schools.

- $\quad$ arrange for special provisions within schools.

- link information flow between education and health sectors.

\section{Social isolation}

This was evident in all twenty five patients and occurred both inside and outside of the family. The reasons ranged from parental fears of the child catching infection, aggressive behaviour of the child, poor acceptance of CWD and their family by the community and sense of shame by parents for meeting extended family and neighbours. Towards encouraging social integration a SSO could:

- encourage formation of support groups/ link to existing support groups

- create individual case plans to encourage CWD participation in family environment and family outings

- provide assistive devices to increase mobility and opportunities

- educate family on importance of social interaction and recreation for the CWD

- allay anxieties through discussion

Poor utilization of governmental and nongovernmental support schemes

Care-givers commonly claimed the CDC to be their only service provider. A considerable number who had received referral to other community based services had never accessed these. The commonest reason given was transport difficulties. Financial hardships and conflicting demands on the care-giver were also mentioned. In such situations the needs of the CWD were often sacrificed. Some had little knowledge of services available or their benefits. Families largely focused their energies on the daily activities of caring for CWD with less importance given to seeking external services. An SSO was able to:

- identify and address barriers to utilization of services

- liaise with allied services

- lobby services to reach CWD and their families

- provide information and referral pathways to existing services

- educate the family on benefits of these services

\section{Lack of respite for care-givers and siblings}

Majority of caregivers appeared to suffer immense emotional stress and had little respite with support from extended family and neighbours being short term. Most care-givers had rarely received the opportunity to discuss the stress they experienced. It was common for care-givers to become upset during 
consultations when discussing how they cope. All parents interviewed had concerns regarding their lack of capacity to cope and reported concerns about impact of disability on siblings. These ranged from lack of attention to missing school. Eighty percent of families said they would benefit from counselling. An SSO could:

- $\quad$ link community support as available

- provide counselling

- $\quad$ provide access to assistive devices so that CWD could be less reliant on caregiver

\section{Conclusions and recommendations}

United Nations Convention on the Rights of the Child states "... a mentally or physically disabled child should enjoy a full and decent life in conditions which ensure dignity, promotes self reliance and facilitates the child's active participation in the community". Sri Lanka is a signatory to this international convention ${ }^{5}$.

The National Policy on disability for Sri Lanka aims to "promote and protect the right s of people who have a disability. They will have opportunities to enjoy a full and satisfying life as equal citizens". Despite this we found that psychosocial issues denied the children of their rights by preventing them access to much needed services.

It is important that children with disabilities access services which promote their physical, social and psychological development. Such services help them to develop their full potential.

Paediatrician led services such as the child development clinic provides medical and related services to disabled children. This article documents how inclusion of a SSO within this multi-disciplinary team would help address many of the complex psychosocial issues outlined above.

It is recommended social services officer be employed to increase efficacy of the service provided in a clinical setting. This would be an effective way to connect government policy to the people it targets ${ }^{6}$.

\section{References}

1. Jonsson T, Wiman R. Education, Poverty and Disability in Developing Countries2001. A Technical Note prepared for Poverty Reduction Sourcebook. Sponsored by the Thematic Group on Disability Issues and Financed by the Finnish Consultant Trust Fund.

2. Groce NE. Adolescents and Youth with Disability: Issues and Challenges. Asia Pacific Disability Rehabilitation Journal 2004; 15(2):13-32.

3. National Policy on Disability for Sri Lanka 2003 Ministry of Social Welfare.

4. Jayathilake R, Amarasuriya H. Save the Children in Sri Lanka 2005: Home Truths: Children's Rights in Institutional Care in Sri Lanka.

5. International Convention of the Rights of the Child 1989; United Nations.

6. Sheila W, Edwards K, Flower J, Yousafzai A. Field testing of the ACCESS materials: a portfolio of materials to assist health workers to identify children with disabilities and offer simple advice to mothers. International Journal of Rehabilitation Research. 2005; 28(4):293-302. 